\title{
Relationship Between Insight, Adherence and Disability in the Diagnose of Paranoid Schizophrenia
}

\author{
Ignacio Garcia-Cabeza ${ }^{1 *}$, Ferreira Victor' ${ }^{1}$ Epifanio Maria $\mathrm{M}^{2}$, Enrique de Portugal ${ }^{1}$ \\ 'Service of Psychiatry, Gregorio Maranon University Hospital, Complutense University of Madrid, Spain \\ ${ }^{2}$ Martin de Vargas Health Center, Spain
}

\section{Article Info}

\section{Article Notes}

Received: December 9, 2018

Accepted: December 28, 2018

\section{*Correspondence:}

Dr. Ignacio García Cabeza, Gregorio Maranon University Hospital, C/ Ibiza, 43, 28009-Madrid, Spain; Email: igcabeza@salud.madrid.org.

(C) 2018 Garcia-Cabeza I. This article is distributed under the terms of the Creative Commons Attribution 4.0 International License.

\section{Keywords}

Insight

Adherence

Disability

Psychosis

\section{Abstract}

The authors review the complex relationship between insight, adherence and symptoms with the functioning of the patient with diagnose of psychosis, either directly or as intermediary factors of each other.

Insight has been proposed to act through symptoms or psychodynamic factors. But in turn, adherence and insight are related in a bidirectional way and the first is one of the best predictors of outcomes in psychosis. Similarly symptoms, especially negative ones, are associated with a worse evolution of the disease.

The authors suggest that insight plays a role in the functioning of the patient, producing both a direct effect and also as a mediator by the improvement of adherence.

It is proposed that insight becomes a key therapeutic target in combined programs in order to favor better outcomes in the evolution of psychosis.

The concept of insight has evolved over the years from psychodynamic positions, related to defense mechanisms (denial or repression), or as well as to the inability to recognize a morbid process by oneself ${ }^{1}$ to a multidimensional model of clinical insight in the 90s, which implied the ability of the patients to recognize their own symptoms, their attribution, its impact on their life and the need for treatment ${ }^{2,3}$.

Beyond the conscience of illness or clinical insight, in the last few years the concept of cognitive insight (understood as the ability to re-evaluate thoughts and beliefs in order to make thoughtful conclusions, focused on more general metacognitive processes) is gaining strength ${ }^{4}$.

At present, an increasing number of authors advocate for a multidimensional, integrative concept of insight in which internal aspects (the already mentioned defense mechanisms), external circumstances, the opinion of others, the patient's own biographical history and cultural background, as well as neuropsychological deficits, should be taken into account ${ }^{5,6}$.

Lack of insight is frequently found among patients with schizophrenia, affecting between $50-80 \%$ of this population ${ }^{7}$. Poor insight has been linked to the clinical course and severity of the illness, greater psychosocial dysfunction, a worsened quality of life, an increased need for involuntary treatments, and greater aggressiveness $^{7-10}$. On the other hand, good insight has been found to be associated with better global functioning ${ }^{11-14}$ and an improved 
personal development in some specific areas, such as social adjustment ${ }^{15-17}$ or working performance ${ }^{18,19}$.

This effect might be due to a mediating role of symptoms ${ }^{7,12}$, but it is equally possible that psychodynamic aspects of insight can also be related to its direct effect on disability.

The finding of a lack of insight could be the result of the use of avoidant coping mechanisms ${ }^{20}$, which the patients with psychosis may also not be able to use in their daily functioning, leading to an ultimate result of greater social and occupational disability. In other words, taking into account more current models, recovery occurs when people with mental illness faced to it feeling empowered, hopeful and in charge of their own recovery ${ }^{21}$, attitudes hindered by the lack of awareness of illness and that would result in an increased disability ${ }^{9}$.

However, it cannot be ignored that good insight has also been related to greater depressive symptoms, suicide, self-stigma, and worse quality of life $\mathrm{f}^{6,9,22-24}$. This apparent paradox might be secondary to the mediation of other factors such as hopelessness, perceived discrimination, the decrease of self-esteem, and internalized stigma ${ }^{6}$. Therefore greater insight in the context of low stigma might be associated with better prognosis ${ }^{25,26}$, while poorer outcomes may occur when insight increases depressive symptoms ${ }^{27}$.

Nonadherence to pharmacological treatment is another common concern in schizophrenia and one of the best predictors of functional outcomes in these patients with this diagnose $\mathrm{e}^{15}$. It has been possible to objectify the negative impact of nonadherence on the course of the illness, resulting in a higher frequency of relapses and rehospitalizations, on the patients' physical health and functioning, as well as on financial consequences for society $^{28}$.

Poor insight has been identified as the main reason for nonadherence in quantitative $\mathrm{e}^{29,30}$ and qualitative studies ${ }^{31}$. The explanation for this association has been posited to be that better insight leads to better attitudes towards medication, leading to improved adherence and therefore, better therapeutic outcomes ${ }^{32}$.

Beck et al. (2011) showed that insight influences adherence in patients with schizophrenia, and, as a result of this, it improves the perception of the need for antipsychotic medication by the patients themselves. On the contrary, it has been observed that lack of insight is generally related to poorer adherence to medication, reduced therapeutic relationship with the therapist and a greater likelihood of relapse ${ }^{30}$. In addition, it has been found that non-adherence to pharmacological treatment also seems to directly contribute to a worse response to the treatment as a whole (both pharmacological and psychosocial treatments); all of this leading to a poorer illness evolution and prognosis ${ }^{33}$.

Otherkey element in disability in paranoid schizophrenia are psychotic symptoms, mainly the negative ones, which are considered essential to schizophrenia and have been significantly related to patients' functioning and quality of life $^{34}$. Its association with both adherence or insight is nonexistent, inconclusive or weak in most of the studies ${ }^{29,35}$, so it is easy to think that they are directly related to disability.

Symptoms severity and attitudes towards medication predict both outcome ${ }^{36}$ and treatment adherence ${ }^{37}$. Several studies report a lack of association between negative symptoms and adherence or a very weak association between both variables ${ }^{32}$. In addition, studies regarding the association of negative symptoms with insight have been in general scarcely consistent, with some studies finding no relationship, and others reporting inconsistent correlations $^{38}$.

Thus, the evidence available suggests that insight, symptoms, and adherence might be related to disability in patients with schizophrenia. In fact, all the studies cited draw conclusions from authors' opinions versus statistically significant results. There are few studies that propose an adequate methodology to support these assertions with a statistical correlation. In truth, the meta-analysis of Lincol et al (2007) found that insight is directly or partially related to global functioning in 13 of 18 reviewed crosssectional studies, as well as in the 5 longitudinal ones ${ }^{7}$. The authors concluded that insight constitutes a key predictor of current functioning, assuming Schwartz et al.'s results (1997), one of the studies reviewed, who found that initial insight predicts improved functioning at 2 years in a longitudinal study, and that this effect might be due to a mediating role of symptoms ${ }^{12}$. This fact was questioned in a 12-month follow-up study carried out in Nederlands where illness insight was associated with change in outcomes, independent from symptom severity, although markedly ill patients had a more negative perception of their quality of life ${ }^{39}$.

The first investigation, as far as we know, that proposes a study of mediation to determine how insight, adherence and functioning are related in patients with a diagnosis of schizophrenia and bipolar disorder is the one published in 2015 by Novick et al. These authors found in a 1-year longitudinal study that insight had an impact on treatment adherence and therapeutic alliance, as well as on global functioning and this effect of insight on global functioning could be modified by adherence to treatment. They also noticed that the effect of insight on global functioning could be modified by adherence to treatment ${ }^{40}$.

Our own research corroborates these results in a more homogeneous sample, patients with paranoid 


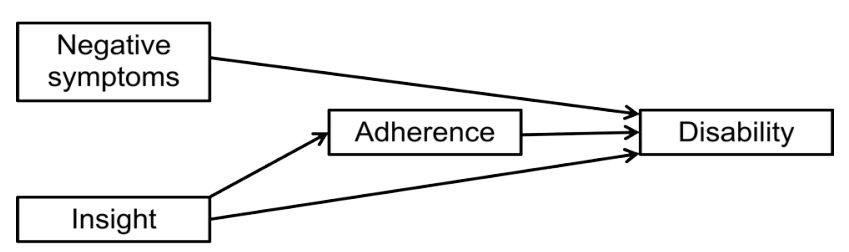

Figure 1. Resulting model from the mediation analysis assessing the effect of negative symptoms, insight and adherence on disability

schizophrenia diagnosis. We found that poor insight plays a major role in the disability in patients with paranoid schizophrenia and that this response is in part mediated by the effect of this poor insight on poor treatment adherence. It should be added that negative symptoms are associated with greater disability in this clinical population too (figure $1)^{41}$.

In our study, we use a multidimensional concept of insight, as described above, and the Scale of Unawareness of Mental Disorder (SUMD) to be assessed ${ }^{3}$. We also chose the disability scale of the World Health Organization (DASWHO) as the main outcome measure instead of Global Assessment Functioning (GAF), the one used by Novick et al $(2015)^{40}$. It should be noted, the GAF also assess symptoms and the collective weight of this measure can distort the interpretation of results on functioning. The decision to use the DAS-WHO scale provided us with an objective and clinically relevant measure of a patient's deficit, and its direct impact on the capacity to perform basic daily activities in the terms self-care, family relationships, occupational and social role; rather than with indirect measures, such as relapses, rehospitalizations, quality of life or even the $\mathrm{GAF}^{41}$.

Along the lines of these findings, a broad and exhaustive theoretical review has been carried out recently by Lysaker et al (2018a). They have studied how insight influences the illness outcome and concluded, with a relatively solid conviction, that poorer insight can lead to a greater likelihood of rejecting antipsychotic medication and greater difficulties in forming a therapeutic alliance ${ }^{6}$.

This paper intends to assess the clinically relevant question of the association between insight, adherence and functional outcome in schizophrenia. However, all the work done through the years would not make any sense unless we correlate it with its importance in clinical care. These findings lead us to believe that insight should become a key therapeutic target in the treatment of patients with schizophrenia, given its proven, direct influence on patient functioning, as well as its effect on adherence to pharmacological treatment.

Most of the once existing therapies oriented to insight in its classical conception - based on psychodynamic positions-, have been condemned to oblivion for their lack of efficacy and efficiency ${ }^{42}$. We could assume that is the reason why current theories are focusing their efforts on the present time, combining strategies of both support and introspection ${ }^{43}$, trying to take some advantage of the positive effect that self-knowledge produces on clinical insight. These current theories are also striving to understand the patient in his biographical context by integrating the psychotic experiences, affirming the limits of the ego and helping the process of individuation ${ }^{5}$; then showing some degree of efficacy even in patients with psychosis ${ }^{44}$.

Our work is focused on clinical insight, but we cannot ignore other aspects of it, not reviewed in this paper, such as cognitive insight, and its importance in the evolution of the illness ${ }^{45,46}$. Similarly other models of therapeutic interventions, the cognitive and metacognitive ones, could favor improving both clinical and cognitive insight by promoting adherence to the pharmacological treatment, insofar as they increase awareness of the usefulness of treatment and one's own difficulties, favoring cognitive flexibility and diminishing hopeless ${ }^{45-49}$.

Therefore, including components aimed at enhancing metacognition, self-esteem, and reducing self-stigma may be useful in therapeutic programs for psychosis. In this sense, there is growing evidence that improving the metacognitive capacity in these patients promotes recovery by enhancing their ability to cope with the difficulties of daily life and better understand themselves and others ${ }^{50}$.

The greatest scientific evidence in relation to the effectiveness of interventions on insight finds that the implementation of comprehensive psychotherapeutic programs, including at least psychoeducation, social skills training and cognitive-behavioral therapy is much more effective than any other intervention by itself. These interventions have not been shown to increase depressive symptoms, one of the already mentioned risks of improving insight ${ }^{51}$.

As a way of conclusion, we want to point out that insight is a key element in schizophrenia outcomes through its direct effect on disability and adherence. It is absolutely necessary to assess it in any patient with psychosis as well as to involve those patients with poorer insight in comprehensive treatment programs to increase insight and improve outcomes.

\section{Conflicts of Interest and Source of Financing}

IGC has received fees from Janssen-Cilag and LundbeckOtsuka SL. This study was funded in part by a FIS (PI11/002849) grant.

\section{References}

1. Lewis A. The psychopathology of insight. J Nerv Ment Dis. 1934; 14: 332-48. 
2. David AS. Insight and psychosis. Br J Psychiatry. 1990; 156: 798-828. doi: https://doi.org/10.1192/pb.17.8.501.

3. Amador XF, Strauss DH, Yale SA, et al. Awareness of illness in schizophrenia. Schizophr Bull. 1991; 17: 113-32.

4. Martin JM, Warman DM, Lysaker PH. Cognitive insight in nonpsychiatric individuals and individuals with psychosis: an examination using the Beck Cognitive Insight Scale. Schizophr Res. 2010; 121: 39-45.

5. García Cabeza I, González de Chávez M. Insight and therapeutic factors in group psychotherapy for schizophrenic outpatients. Psychosis 2009; 1: 134-144.

6. Lysaker PH, Pattison ML, Leonhardt BL, et al. Insight in schizophrenia spectrum disorders: relationship with behavior, mood and perceived quality of life, underlying causes and emerging treatments. World Psychiatry. 2018a; 17(1): 12-23. doi: 10.1002/wps.20508

7. Lincoln TM, Lüllmann E, Rief W. Correlates and Long-Term Consequences of Poor Insight in Patients With Schizophrenia. A Systematic Review. Schizophr Bull. 2007; 33: 1324-1342. https://doi. org/10.1093/schbul/sbm002.

8. Gharabawi G, Cynthia Bossie C, Turkoz I, et al. The impact of insight on functioning in patients with schizophrenia or schizoaffective disorder receiving risperidone long-acting injectable. J Nerv Ment Dis. 2007; 195: 976-982.

9. Lysaker PH, Vohs J, Hillis JD, et al. Poor insight into schizophrenia: contributing factors, consequences and emerging treatment approaches. Expert Rev Neurother. 2013; 13; 785-793. doi:https:// doi.org/10.1586/14737175.2013.811150.

10. Ouzir M, Azorin JM, Adida M, et al. Insight in schizophrenia: From conceptualization to neuroscience. Psychiatry and Clinical Neurosciences. 2012; 66: 167-179. https://doi.org/10.1111/j.14401819.2012.02325.x

11. Klaas HS, Clémence A, Marion-Veyron R, et al. Insight as a social identity process in the evolution of psychosocial functioning in the early phase of psychosis. Psychol Med. 2017; 47: 718-719.https://doi. org/10.1017/s0033291716002506.

12. Schwartz RC, Cohen BN, Grubaugh A. Does insight affect long-term inpatient treatment outcome in chronic schizophrenia. Compr Psychiatry. 1997; 38: 283-288. doi: https://doi.org/10.1016/s0010440x(97)90061-4.

13. Simon AE, Berger GE, Giacomini $\mathrm{V}$, et al. Insight in relation to psychosocial adjustment in schizophrenia. J Nerv Ment Dis. 2004; 192: 442-445. doi:https://doi.org/10.1097/01 nmd.0000130137.85640.70.

14. Stefanopoulou E, Lafuente AR, Saez Fonseca JA, et al. Insight, global functioning and psychopathology amongst in-patient clients with schizophrenia. Psychiatr Q. 2009; 80: 155-165. doi: https://doi. org/10.1007/s11126-009-9103-9.

15. Bernardo M, Cañas F, Herrera B, et al. Adherence predicts symptomatic and psychosocial remission in schizophrenia: Naturalistic study of patient integration in the community. Rev Psiquiatr Salud Ment. 2017; 10(3): 149-159. doi: 10.1016/j.rpsm.2016.04.001.

16. Soskis DA, Bowers MB. The schizophrenic experience. A follow-up study of attitude and post hospital adjustment. J Nerv Ment Dis. 1969; 149: 443-449. doi: https://doi.org/10.1097/00005053-196912000-00001.

17. Yen CF, Yeh ML, Chen CS, et al. Predictive value of insight for suicide, violence, hospitalization, and social adjustment for outpatients with schizophrenia: a prospective study. Compr Psychiatry. 2002; 43: 443447. doi: https://doi.org/10.1053/comp.2002.35901.

18. Lysaker PH, Bryson GJ, Bell M. Insight and work performance in schizophrenia. J Nerv Ment Dis. 2002; 190: 142-146. https://doi. org/10.1097/00005053-200203000-00002.
19. Erickson M, Jaafari N, Lysaker P. Insight and negative symptoms as predictors of functioning in a work setting in patients with schizophrenia. Psychiatry Res. 2011; 189: 161-165. doi: https://doi. org/10.1016/j.psychres.2011.06.019.

20. Middelboe T, Mortensen EL. Coping strategies among the longterm mentally ill: Categorization and clinical determinants. Acta Psychiatr Scand. 1997; 96: 188-194. doi: https://doi. org/10.1111/j.1600-0447.1997

21. Silverstein SM, Bellack AS. A scientific agenda for the concept of recovery as it applies to schizophrenia. Clin Psychol Rev. 2008; 28: 1108-1124. doi: https://doi.org/10.1016/j.cpr.2008.03.004.

22. Drake RJ, Pickles A, Bentall RP, et al. The evolution of insight, paranoia and depression during early schizophrenia. Psychol Med. 2004; 34(2): 285-92.

23. Hasson-Ohayon I, Kravetz S, Roe D, et al. Insight into psychosis and quality of life. Compr Psychiatry. 2006; 47(4): 265-9.

24. Lien YJ, Chang HA, Kao YC, et al. Insight, self-stigma and psychosocial outcomes in Schizophrenia: a structural equation modelling approach. Epidemiology and Psychiatric Sciences. 2018; 27: 176-185. doi:10.1017/S2045796016000950

25. Hasson-Ohayon I, Kravetz S, Meir T, et al. Insight into severe mental illness, hope, and quality of life of persons with schizophrenia and schizoaffective disorders. Psychiatry Res. 2009; 167: 231-8. doi: 10.1016/j.psychres.2008.04.019.

26. Lysaker PH, Roe D, Yanos PT. Toward understanding the insight paradox: internalized stigma moderates the association between insight and social functioning, hope, and self-esteem among people with schizophrenia spectrum disorders. Schizophr Bull. 2006; 33(1): 192-199.

27. Margariti M, Ploumpidis D, Economou M, et al. Quality of life in schizophrenia spectrum disorders: associations with insight and psychopathology. Psychiatry Res. 2015: 225(3): 695-701. doi: 10.1016/j.psychres.2014.11.016.

28. Higashi K, Medic G, Littlewood KJ, et al. Medication adherence in schizophrenia: factors influencing adherence and consequences of nonadherence, a systematic literature review. Ther Adv Psychopharmacol.2013;3:200-18. doi:10.1177/2045125312474019.

29. Kao YC, Liu YP. Compliance and schizophrenia: The predictive potential of insight into illness, symptoms, and side effects. Compr Psychiatry. 2010: 51: 557-65. doi: 10.1016/j.comppsych.2010.03.007.

30. Beck EM, Cavelti M, Kvrgic S, et al. Are we addressing the 'right stuff' to enhance adherence in schizophrenia? Understanding the role of insight and attitudes towards medication. Schizophr Res. 2011; 132: 42-9. doi: https://doi.org/10.1016/j.schres.2011.07.019.

31. Velligan DI, Sajatovic M, Hatch A, et al. Why do psychiatric patients stop antipsychotic medication? A systematic review of reasons for nonadherence to medication in patients with serious mental illness. Patient Preference and Adherence. 2017; 11: 449-468. doi: 10.2147/ PPA.S124658.

32. Mohamed S, Rosenheck R, McEvoy J, et al. Cross-sectional and Longitudinal Relationships Between Insight and Attitudes toward Medication and Clinical Outcomes in Chronic Schizophrenia. Schizophr Bull. 2009; 35: 336-346. https://doi.org/10.1093/schbul/ sbn067.

33. Lindenmayer JP, Liu-Seifert H, Kulkarni PM, et al. Medication nonadherence and treatment outcome in patients with schizophrenia or schizoaffective disorder with suboptimal prior response. J Clin Psychiatry. 2009; 70: 990-6. doi: 10.4088/JCP.08m04221.

34. Foussias G, RemingtonG. Negative symptoms in schizophrenia: avolition and Occam's razor. Schizophr Bull. 2010; 36: 259-269.

35. Boban J, Janardhanan C, Narayanaswamy JC, et al. Insight in 
schizophrenia: relationship to positive, negative and neurocognitive dimensions. Indian J Psychol Med. 2015; 37: 5-11. doi: 10.4103/02537176.150797 .

36. Malla AK, Norman RM, Manchanda R, et al. Symptoms, cognition, treatment adherence and functional outcome in first-episode psychosis. Psychol Med. 2002; 32(6): 1109-19.

37. Baloush-Kleinman V, Levine SZ, Roe $\mathrm{D}$, et al. Adherence to antipsychotic drug treatment in early-episode schizophrenia: a sixmonth naturalistic follow-up study. Schizophr Res. 2011;130. 176-81.

38. Segarra R, Ojeda N, Peña J, et al. Longitudinal changes of insight in first episode psychosis and its relation to clinical symptoms, treatment adherence and global functioning: one-year follow-up from the Eiffel study. Eur Psychiatry. 2012; 27(1): 43-9. doi: 10.1016/j. eurpsy.2010.06.003.

39. Van Baars AWB, Wierdsma AI, Hengeveld MW, et al. Improved insight affects social outcomes in involuntarily committed psychotic patients: A longitudinal study in the Netherlands. Comprehensive Psychiatry. 2013; 54: 873-879.

40. Novick N, Montgomery W, Treuer T, et al. Relationship of insight with medication adherence and the impact on outcomes in patients with schizophrenia and bipolar disorder: results from a 1-year European outpatient observational study. BMC Psychiatry. 2015; 15: 189.

41. García Cabeza I, Díaz-Caneja C, Ovejero M, et al. Insight, adherence and disability in paranoid schizophrenia. Psychiatry Res. 2018; 270: 274-280.

42. Gunderson JG. Effects of psycotherapy in schizophrenia: comparative outcome of two forms of treatment. Schizophr Bull. 1984; 10: 564598.
43. McGlashan TH. What has become of the psychotherapy of schizophrenia. Acta Psychiatr Scand. 1994; 90 (supl. 384): 147-152.

44. Mojtabai R, Malaspina D, Susser E. (2003). The concept of population prevention: application to schizophrenia. Schizophr Bull. 2003; 29(4): 791-801.

45. Garety P, Fowler D, Kuipers E, et al. London-East Anglia randomised controlled trial of cognitive behavioural tharapy for psychosis: II Predictors of outcome. Br J Psychiatry. 1997; 171: 420-426.

46. Emmerson LC, Granholm E, Link PC, et al. Insight and treatment outcome with cognitive behavioral social skills training for older people with schizophrenia.J Rehabil Res Dev. 2009; 46(8): 1053-1058.

47. Bora E. Relationship between insight and theory of mind in schizophrenia: A meta-analysis. Schizophr Res. 2017; 190: 11-17. doi: 10.1016/j.schres.2017.03.029.

48. Chan KK.Associationsof symptoms, neurocognition, andmetacognition with insight in schizophrenia spectrum disorders. Compr Psychiatry. 2016; 65: 63-9. doi: 10.1016/j.comppsych.2015.09.009.

49. Ng R, Fish S, Granholm E. Insight and theory of mind in schizophrenia. Psychiatry Res. 2015; 225(1-2): 169-174. doi: 10.1016/j. psychres.2014.11.010.

50. Lysaker PH, Hamm JA, Hasson-Ohayon I, et al. Promoting recovery from severe mental illness: Implications from research on metacognition and metacognitive reflection and insight therapy. World J Psychiatry. 2018b; 8(1): 1-11.doi: 10.5498/wjp.v8.i1.1.

51. Pijnenborg GHM, van Donkersgoed RJM, David AS, et al. Changes in insight during treatment for psychotic disorders: A meta-analysis. Schizophr Res. 2013; 144: 109-117. doi: https://doi.org/10.1016/j. schres.2012.11.018. 